\title{
PERSPECTIVA TERAPÊUTICA DA PEDAGOGIA DO OPRIMIDO DE PAULO FREIRE: UMA LEITURA FENOMENOLÓGICO- EXISTENCIALISTA
}

\section{THE THERAPEUTIC PERSPECTIVE OF THE PEDAGOGY OF THE OPPRESSED OF PAULO FREIRE: A PHENOMENOLOGICAL- EXISTENTIAL READING}

\author{
Raisa Grasiele Rodrigues de Almeida \\ Emmanoel de Almeida Rufino
}

\begin{abstract}
RESUMO: Neste estudo, acolhemos as leituras freirianas sobre o fenômeno educacional transpondo-as metaforicamente ao setting terapêutico, por considerarmos que há certa similaridade entre esses espaços de formação do ser: formal ou informalmente, ambos são ambientes de ensino-aprendizagem. As reflexões que Paulo Freire desenvolve na obra Pedagogia do oprimido nos apontam prismas provocadores e pertinentes à experiência terapêutica que floresce entre psicólogos(as) e clientes e, conforme pretendemos evidenciar neste estudo, dialogam coerentemente com uma abordagem - em especial - na área da psicologia: a abordagem centrada na pessoa (ACP) de viés fenomenológico-existencialista. Diante disso, a problemática que guia este estudo assim se revela: como a obra Pedagogia do oprimido pode nos ajudar a pensar experiências terapêuticas num viés fenomenológico-existencialistas? As discussões desenvolvidas nos levam a uma compreensão mais apurada a respeito do horizonte de ação/atuação dos profissionais da educação e da psicologia nos seus ambientes terapêuticos. Dentre as muitas conclusões a que nos apontam a presente investigação, destacamos a importância da construção intersubjetiva de interações dialógicas vertidas à promoção emancipatória de si e do outro, cenário que, dentre outras coisas, pretere relações de opressão por considerar que todos os envolvidos em settings terapêuticos e em salas de aula têm algo a aprender com o outro.
\end{abstract}

Palavras-chave: Paulo Freire. Pedagogia do oprimido. Terapia fenomenológicoexistencialista.

ABSTRACT: In this study, we assume the Freirean interpretations about the educational phenomenon, transposing them metaphorically to the therapeutic setting, considering that there is a certain similarity between these spaces of formation of the being: formally or informally, both are teaching-learning environments. The reflections that Paulo Freire develops in the work Pedagogy of the oppressed point us prisms provoking and pertinent to the therapeutic experience that flourishes between psychologists and clients and, as we want to show in this study, dialogues coherently with an approach - especially - in the area of psychology: the person-centered approach (ACP) of phenomenological-existentialist bias. Faced with this, the problem that guides this study reveals itself: how can Pedagogy of the Oppressed help us to think of therapeutic experiences in a phenomenological-existentialist bias? The discussions developed lead us to a more accurate understanding of the horizon of action /

Educação, Psicologia e Interfaces, Volume 2, Número 1, p.38-46, Janeiro/Abril, 2018 
performance of education and psychology professionals in their therapeutic environments. Among the many conclusions that the present investigation points out to us, we emphasize the importance of the intersubjective construction of dialogical interactions with the emancipatory promotion of oneself and of the other, a scenario that, among other things, pretere relations of oppression, considering that all those involved in settings and classrooms have something to learn from each other.

Keywords: Paulo Freire. Pedagogy of the oppressed. Phenomenological-existentialist therapy.

\section{INTRODUÇÃO}

As propostas educativas de Paulo Freire em sua obra Pedagogia do Oprimido nos instiga à reflexão de temas como autonomia, conscientização, intensa reflexão do funcionamento de nossas classes sociais, as interações entre opressor e oprimido, as relações de poder das classes dominantes na sociedade, etc., insights que nos possibilitam criar pontes críticas para além do espaço educativo escolar. Neste estudo, acolhemos as leituras freirianas sobre o fenômeno educacional transpondo-as metaforicamente ao setting terapêutico, por considerarmos haver certa similaridade entre esses espaços de formação do ser: formal ou informalmente, ambos são ambientes de ensino-aprendizagem.

Nesses termos, sugerimos que as propostas educacionais construídas por Paulo Freire nos clareiam caminhos eficazes não só para reflexões em torno de uma tipologia pedagógica eficiente às demandas de dentro e de fora do ambiente escolar: essas reflexões nos orientam prismas provocadores e pertinentes à experiência terapêutica que floresce entre psicólogos(as) e clientes e, conforme pretendemos evidenciar neste estudo, dialogam coerentemente com uma abordagem - em especial - na área da psicologia: a abordagem centrada na pessoa (ACP) de viés fenomenológicoexistencialista.

Diante disso, a problemática que guiará este estudo será a seguinte: como a obra Pedagogia do oprimido pode nos ajudar a pensar experiências terapêuticas num viés fenomenológico-existencialistas? Diante disso e objetivando compreender como a

Educação, Psicologia e Interfaces, Volume 2, Número 1, p.38-46, Janeiro/Abril, 2018

ISSN: 2594-5343 DOI: https://doi.org/10.37444/issn-2594-5343.v2i1.69 
referida obra freiriana nos apresenta ideias fenomenológico-existencialistas (especialmente quando associamos a figura do educador ao de um terapeuta), organizaremos o presente estudo - em vista da consecução desse escopo geral - em duas etapas específicas de análise: primeiramente, explicitaremos e discutiremos conceitos fundamentais no âmbito da fenomenologia afim de que, no segundo momento, desenvolvamos o exame da pedagogia do oprimido à luz dos mesmos conceitos.

Acreditamos que tais discursões nos levarão a uma compreensão mais adequada a respeito do horizonte de ação/atuação dos profissionais de educação e da psicologia nos seus ambientes terapêuticos (especialmente se consideramos o sentido do termo grego terapia, "abrir portas"). Junto a isso, acreditamos que essas reflexões também nos possibilitarão refletir formas possíveis de como nos tornarmos uma sociedade mais livre. Este estudo nos provoca a redimensionar nossa visão a respeito de profissionais que fazem uso da "arma" do saber-poder em setting terapêutico, limitando o sujeito e toda sua existência (embora seja objetivo da terapia devolver autonomia do sujeito).

\section{MATERIAL E MÉTODO}

A metodologia que referência o nosso estudo segue uma tipologia teórica de caráter bibliográfico. Diante disso, a fim de interseccionarmos a obra de Paulo Freire (2017) e o pensamento fenomenológico (na perspectiva existencialista), alcançando, pois, nossa meta geral, faremos uso das obras "Ser e tempo" (HEIDEGGER, 1988), “Carl Rogers” (ZIMRING, 2010), "Fenomenologia da percepção” (MERLEAU-PONT, 2006) e "Ensaios sobre fenomenologia" (Cf. LIMA, 2014).

\section{RESULTADOS E DISCUSSÃO}

$\mathrm{Na}$ esfera fenomenológico-existencialista, o foco é o fenômeno, abarcado como o que se revela em suas formas de se revelar, consentindo a um olhar em sua totalidade, de forma especifica, sem interrupção de conceitos antecipados que venha trazer qualquer definição a respeito, assim também sem embasamento teórico prévio que enquadre o que se foi revelado.

Educação, Psicologia e Interfaces, Volume 2, Número 1, p.38-46, Janeiro/Abril, 2018 
A fenomenologia se apresenta, em uma posição mantida por aquele que interroga, de modo que o interrogador-fenomenólogo se direciona para o sujeito tendo em foco o fenômeno da experiência apresentado pelo cliente: "a fenomenologia procura examinar a experiência humana de forma rigorosa com uma ciência descritiva. Desta maneira a reflexão se faz necessária, afim de tornar possível observar as coisas tal como elas se manifestam e descrevê-las" (Cf. LIMA, 2014, p. 12). Essa citação nos traz a ideia de que existe um mundo ao redor do fenomenal, surgindo e doando-se ao pesquisador que enfatiza o fenômeno. A abordagem fenomenológico-existencialista acredita na necessidade de o pesquisador ir-às-coisas-mesmas, não tendo em vista um objeto concreto, estagnado, fenomenal, que se apresenta diante dos olhos, mas como forma desse fenomenal se permitir à experiência do "ver" do pesquisador, o que justificaria a nomenclatura dada à fenomenologia, sendo aquilo que se revela $($ phenomenos $+\operatorname{logos})$. Apesar disso, para a fenomenologia, sujeitos e objetos não são espaçados, embora já estejam ontologicamente unidos, partindo do princípio que o ser é sempre um ser-no-mundo.

A educação centrada no aluno é aquela focada primeiramente na realização do ser do estudante, cujo objetivo é auxiliar o sujeito a se tornar humano, internalização de atualização de suas possibilidades, tendência essa de atualização que Rogers frisa bem. Assim podemos, trazer essa ideia de educação centrada na pessoa para o setting terapêutico, onde o terapeuta tem como foco o cliente, sendo um facilitador do seu processo, de buscar conhecer a si mesmo, internalizando a possibilidade de significar e resinificar seu sofrimento e suas angústias. Embora o modelo humanista de educação seja algo acessível a todos profissionais, ainda sim, isso nos implica reconhecer que esse é um modelo muito distante da prática real de alguns deles.

Podemos refletir a respeito do que Freire chama de educação bancária, trazendo para perspectiva de terapia bancária, na qual a educação/terapia se torna um ato de depositar em que os educandos/clientes são os repositores e o educador/terapeuta são os depositantes, de modo que, ao invés de comunicar-se, o educador/terapeuta faz "comunicados" e depósitos que os educandos/clientes, meras incidências, recebem pacientemente, memorizam e repetem (Cf. FREIRE, 2017, p. 80).

Eis aí a concepção "bancária” da educação, "em que a única margem de educação que se oferece aos educandos é a de receberem os depósitos guarda-los e

Educação, Psicologia e Interfaces, Volume 2, Número 1, p.38-46, Janeiro/Abril, 2018 
arquivá-los" (Ibid., p. 80). Assim precisamos ter cuidado para não tornar o processo terapêutico um mero depósito de "receitas" (técnicas) prontas, na qual o cliente/aluno só recebe tudo que o terapeuta deposita.

A esse respeito, Freire (2017, p. 89) nos diz: "Entre permanecer porque desparece, numa espécie de morrer para viver, e desaparecer pela e na imposição de sua presença, o educador 'bancário' escolhe a segunda hipótese"; tal pensamento nos remete a um modelo terapêutico a base de termos anestésicos, receitas prontas e meramente técnicas, em que o terapeuta escolhe "desaparecer" na relação (como "objeto" que é parte dela), para impor seu conhecimento ocupando sua posição de saber-poder, entrando assim, na cabine terapêutica, não havendo possibilidade de terapia já que na “cabine do terapeuta”, não há espaço para o cliente, pois já não se trata da necessidade do cliente que está em questão, e sim a necessidade de autossuficiência do terapeuta.

Esse modelo de educação/terapia à base de conotação "digestiva" constrói barreiras no pensar verdadeiro. Não vai ser mastigando e entregando "mastigado" dando para o cliente engolir o conteúdo da terapia sem que ele mesmo precise "mastigar" (sofrer) o conteúdo, sentir o seu dissabor, tendo em vista que esse processo demanda do sujeito uma grande concentração de energia vital. Em sua obra Pedagogia do oprimido, Paulo Freire vai nos trazer uma reflexão mais precisa a respeito da falta de uma pedagogia eficiente na formação do sujeito na nossa sociedade.

$\mathrm{Na}$ referida obra, Paulo Freire evidencia caminhos para se constituir uma educação centrada no aluno. Nela, o educador/ terapeuta é convidado a se permitir fazer uma experiência de conexão relacional com o educando/cliente. Para viabilizar esse processo, Freire adverte sobre a necessidade do educando/cliente conquistar sua autonomia, pressuposto fundamental para que consiga estabelecer uma relação dialógica (horizontal) com o educador/terapeuta. Nesse sentido,

A ação libertadora, pelo contrário, reconhecendo esta dependência dos oprimidos como ponto vulnerável, deve tentar, através da reflexão e da ação, transforma-la em independência. Esta, porém, não é doação que uma liderança, por mais bem intencionada que seja, lhes faça. Não podemos esquecer que a libertação dos oprimidos é a libertação de homens e não de "coisas". Por isto, se não é autolibertação - ninguém se liberta sozinho -, também não é libertação de uns feita por outros (Cf. FREIRE, 2017, p. 74),

Educação, Psicologia e Interfaces, Volume 2, Número 1, p.38-46, Janeiro/Abril, 2018 
A partir da reflexão supracitada, embora um sujeito precise do outro para achar sua liberdade, sua liberdade não está a depender do outro. Por isso, diz Freire (2017, p. 76):

É como homens que os oprimidos têm que lutar, e não como "coisas". É precisamente porque reduzidos a quase "coisas", na relação de opressão em que estão, que se encontram destruídos. Para reconstruirse, é importante que ultrapassem do estado de quase "coisas". Não podemos comparecer a luta como quase "coisas" para depois serem homens.

Este pensamento nos remete a Heidegger porque nos faz refletir a coisificação do ser pelo processo de redução do sujeito a um ente, ou seja, é preciso assumir a posição de humanos que somos, para assim lutar como tal, e não ser como máquinas, programadas, mensuráveis. Somos um dasein (ser aî) lançado no mundo, constituídos por natureza própria (ou seja, ontológico). Somos essência: o ser não se explica nem se programa; qualquer tentativa de explicação do ser reduzirá ele a um ente. Em uma relação opressora, o oprimido desconhece o dasein que ele é no mundo, de modo que seria impossível o sujeito-oprimido criar uma dialética com o mundo (entre o mundo que ele é e o mundo que existe fora), ou seja, não seria livre.

O ser aí se torna um ser no mundo a partir do momento que é lançado no mundo. Assim, ele se transforma em um ser comum, ser com outros seres que fazem parte de um coletivo. Muitos dos seres se endureceram, causando um distanciamento do ser, transformando o indivíduo em coisas, em parafusos (como diria Aristóteles), parafusos que servem para apertar toda mecânica cosmológica. A relação do eu-tu se compara a parafusos que funcionam para ajustar o universo. Em uma relação opressora não tem como haver crescimento de nenhuma das partes.

Heidegger vai nos deixar claro à importância de "se tornar visível o ser-nomundo, no tocante a seu momento estrutural "mundo" (Cf. HEIDEGGER, 1988, p. 103). Uma vez que anulamos o ser, reduzindo o sujeito a um ente e, assim, coisificando esse ser, o mesmo é anulado em sua liberdade, criatividade e subjetividade. Sendo assim, podemos pensar na ideia de uma pessoa coisificada, destruída. Uma vez que o educador/terapeuta não leva em conta toda existência (experiência do aluno/paciente), ocorre uma impedimento de o aluno/cliente chegar a si mesmo, até porque existir é

Educação, Psicologia e Interfaces, Volume 2, Número 1, p.38-46, Janeiro/Abril, 2018

ISSN: 2594-5343 DOI: https://doi.org/10.37444/issn-2594-5343.v2i1.69 
tornar-se consciente de si mesmo, é dá sentido novo à vida, impossibilitando esse ser viver a mundanidade.

Ressaltando que "mundo possui aqui, um significado pré-ontologicamente existenciário. Deste sentido, resultam diversas possibilidades: mundo ora indica mundo "público do nós." ora o mundo circundante mais próximo (doméstico) e "próprio (Cf. HEIDEGGER, 1988, p. 105) Sendo assim, o mundo significa o conceito existencialontológico da mundanidade. Ora, se até mundanidade pode modificar-se e transformarse segundo Heidegger, quem dirá um sujeito carregado de sentimentos, criatividade, percepções e subjetividade, sendo parte dessa mundanidade, porque impedir desse aluno/cliente vivenciar tudo isso? De ser de fato um dasein?

No momento em que o ser humano se assume como um ser existencial, ele é tensionado a buscar saberes que lhe façam conhecer mais sobre o mundo que lhe rodeia, o que nos remete à explicação de Heidegger ao responder o que poderia significar descrever o mundo como fenômeno: "seria deixar e fazer ver o que se mostra no "ente" dentro do mundo" (Cf. HEIDEGGER, 1988, p. 103).

O conhecimento de si é parte fundamental da vontade humana de florescer na busca pelo que tornam criativas - e dão sentido a - suas experiências de vida. É somente no percorrer de sua existência que o ser se descobre, vivenciando dificuldades, riscos, dúvidas; são esses conflitos que possibilitam o homem a chegar a sua compleição moral e consequentemente ao crescimento espiritual. Isso assim também era percebido por Carl Rogers: o indivíduo humano como uma totalidade, um organismo em pleno desenvolvimento de integração.

Rogers considerava fundamental atentar aos sentimentos e à experiência como elementos cruciais para o crescimento subjetivo humano, considerando o sujeito como um complexo de mente e corpo. Rogers (2010, p. 37) defendia que em cada indivíduo havia uma construção autônoma e interna que lhe permitia dar significado a algo e a fazer opções. Para ele, o mundo existe a partir da percepção do homem que recebe os estímulos e lhes atribui significado.

Existe um potencial libertador em cada sujeito. Professor/terapeuta se tornam facilitadores na busca da autonomia do aluno/paciente, embora a liberdade desses sujeitos não esteja encerrada no outro, já que se assim o fosse, nenhum deles estaria livre, porque dependeriam doa boa-vontade do outro para tal. Diante disto, podemos

Educação, Psicologia e Interfaces, Volume 2, Número 1, p.38-46, Janeiro/Abril, 2018 
compreender que o mesmo sujeito (educador ou terapeuta) pode ser uma ferramenta para facilitar a busca da liberdade do sujeito, na retomada de sua autonomia. Em contrapartida, o sujeito pode se tornar um opressor do oprimido ao direcionar, determinar, tornando-o dependente do saber-poder assumido pelo educador/terapeuta.

Vale ressaltar que de nada adiantaria o educador/terapeuta falar que o outro é livre se o próprio sujeito (aluno/cliente) não tomar consciência da sua liberdade. Ou seja, segundo Freire (2017, p. 74), "precisamos estar convencidos de que o convencimento dos oprimidos de que devem lutar por sua libertação não é doação (...), mas resultado de sua conscientização". A liberdade não é dada nem pelo destino, nem pelos outros: ela é construída intersubjetivamente, na relação dos sujeitos com todos os outros que compõem seu mundo.

\section{CONSIDERAÇÕES FINAIS}

Cada sujeito constrói de forma subjetiva seus significados e assim faz suas próprias escolhas. A percepção da realidade e do ambiente que o sujeito ocupa é desenvolvida na medida em que ele faz experiências, enquanto um ser lançado no mundo (HEIDEGGER, 1988) e aberto a possibilidades. Nesse sentido, é necessário que se verta um olhar sobre o homem como um ser de capacidades, de modo que todo aquele que busque ensinar alguém deve prever e garantir sua liberdade criativa de ir à procura do sentido de si. Ora, as referidas capacidades de cada sujeito revelam o seu potencial de autonomia, que, na perspectiva fenomenológico-existencialista, deve ser fomentada e garantida por verdadeiros terapeutas (os "abridores de portas", conforme atesta o termo e sua acepção grega).

Tendo como meta auxiliar a autonomia e autoconscientização crítica do educando/cliente, os educadores/terapeutas devem atuar em seus espaços pedagógicoterapêuticos como facilitadores nesse processo de descoberta do caminho de si mesmo.

Este caminho tem de ser criado a partir das concepções existenciais do próprio educando/cliente, numa perspectiva não diretiva, não importando qual seja o caminho e o destino final que esse sujeito-aprendente chegue, desde que o faça de modo autônomo.

Em suma, todos os autores que aqui analisamos nos apontam a importância da construção intersubjetiva de interações dialógicas vertidas à promoção emancipatória de si e do outro, cenário que, dentre outras coisas, pretere relações de opressão por

Educação, Psicologia e Interfaces, Volume 2, Número 1, p.38-46, Janeiro/Abril, 2018 ISSN: 2594-5343 DOI: https://doi.org/10.37444/issn-2594-5343.v2i1.69 
considerar que todos os envolvidos em settings terapêuticos e em salas de aula têm algo a aprender com o outro.

\section{REFERÊNCIAS BIBLIOGRÁFICAS}

FREIRE, Paulo. Pedagogia do oprimido. Rio de Janeiro/São Paulo: Paz e Terra, 2017.

HEIDEGGER, Martin. Ser e tempo. Trad. de Márcia de Sá Cavalcanti. Vol. 1.

Petrópolis: Voes, 1988.

LIMA, Antônio Balbino Marçal. Ensaio sobre a fenomenologia: Husserl, Heidegger e Merleau-Ponty. Ilhéus: Editus, 2014.

MERLEAU-PONTY, Maurice. Fenomenologia da percepção. Trad. de Carlos Alberto Ribeiro de Moura. 3. ed. São Paulo: Martins Fontes, 2006.

ZIMRING, Fred. Carl Rogers. Trad. de Marcos Antônio Lorieri. Recife: Fundação Joaquim Nabuco/Editora Manssangana, 2010.

\section{Credenciais dos autores}

ALMEIDA, Raisa Grasiele Rodrigues de. Graduanda em Psicologia, Faculdade Maurício de Nassau - Brasil. E-mail: rai_gr@hotmail.com.

RUFINO, Emmanoel de Almeida. Doutorado em Educação pela Universidade Federal da Paraíba, professor no Instituto Federal de Educação, Ciência e Tecnologia da Paraíba. E-mail: emmanoel.rufino@ifpb.edu.br

Endereço para correspondência: Raisa Grasiele Rodrigues de Almeida, Rua Professora Cristina Di Lorenzo Marsicano, no 80, Planalto Boa Esperança, CEP: 58065 162, João Pessoa, PB. E-mail: rai_gr@ hotmail.com

Como citar este artigo (Formato ABNT): ALMEIDA, Raisa Grasiele Rodrigues de; RUFINO, Emmanoel de Almeida. Perspectiva terapêutica da Pedagogia do Oprimido de Paulo Freire: uma leitura fenomenológico-existencialista. Educação, Psicologia e Interfaces, v. 2, n.1, 38-46, 2018. DOI: https://doi.org/10.37444/issn-2594-5343.v2i1.69

Recebido: $18 / 02 / 2018$.

Aceito: 26/03/2018.

Educação, Psicologia e Interfaces, Volume 2, Número 1, p.38-46, Janeiro/Abril, 2018 